\title{
Design of a marine drilling riser for the deepwater environment
}

\author{
N. S. Woo, S. M. Han \& Y. J. Kim \\ Korea Institute of Geoscience and Mineral Resources, Korea
}

\begin{abstract}
The development of deepwater oil and gas reserves constantly faces the challenge to reduce costs of all components and activities. A drilling riser is a conduit that provides a temporary extension of a subsea oil well to a surface drilling facility. With an increase in drilling operations in harsh environments, drilling riser requirements and limits have become more onerous due to uncertainties involved in response prediction and prolonged drilling programs. A high level of understanding is required of the response of the system to various conditions, and the design issues that govern the system. This paper presents an overview of the engineering challenges faced in designing drilling riser system for drill ship in water depths of 10,000 ft. Also, Static and dynamic analysis of drilling riser system have been carried out for the development of drilling riser joint. Keywords: marine drilling riser, offshore installation, offshore drilling.
\end{abstract}

\section{Introduction}

In recent years, exploration and production activities of oil and gas in offshore have increased in deep and ultra-deep water. As one of the key elements in offshore infrastructure, deepwater riser technology plays an important role in offshore development. The drilling riser is the key element for drilling in deepwater.

A drilling riser is a tube that can be made of steel, aluminum, titanium or composite materials that is used to conduct drilling, running and setting casing, cementing and coring operations through the seawater column.

Its architecture for deepwater drilling depends on numerous different factors related to operational and environmental conditions. These include water depth, 
mud weight, auxiliary line diameters and working pressures, sea state and current profiles, and maximum rig offset, and so on.

All of the above parameters have to be taken into account in the design of the various riser system components including the main tube, the auxiliary lines, the connectors, the distribution of buoyancy modules, and the tensioning system.

An example of a typical drilling riser system stack-up and drilling riser joint are shown in Fig. 1 [1]. Riser joint main tube and the associated couplings in Fig. 1(b) are generally sized to be compatible with a specific BOP stack size. A riser joint is a large diameter, high strength pipe, either seamless or electric welded, with couplings welded to each end. The main tube is specified by its outside diameter, wall thickness, and material properties.

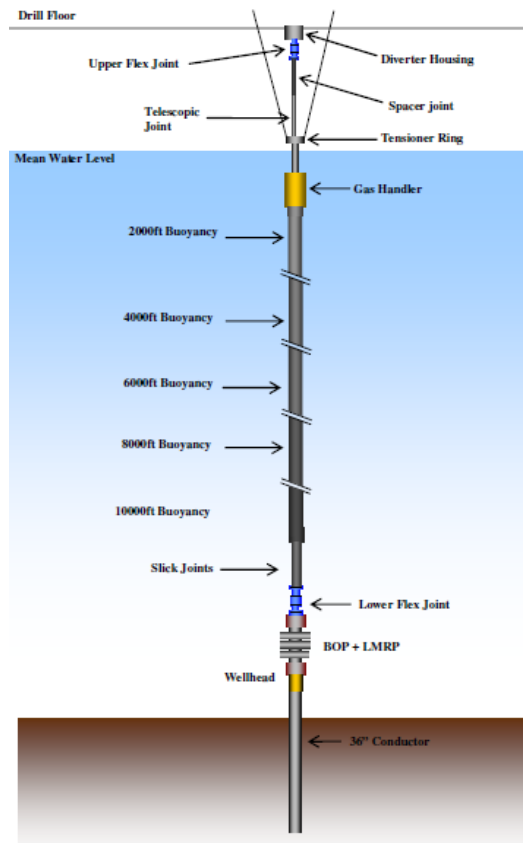

(a) Drilling riser stack-up

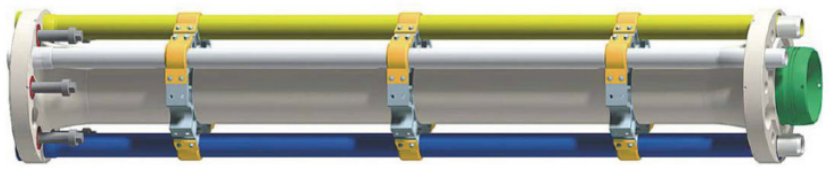

(b) Drilling riser joint

Figure 1: Drilling riser stack-up for 10,000 ft water depth and drilling riser joint.

When the riser system is being deployed, the riser joints are coupled together on the drill floor and lowered into the water. The string of riser joints represents 
the principal component of the riser system and is used to perform the riser system functions.

The push to drill in harsh, deepwater environments makes the need for an optimum riser stack-up that can maximize operability envelopes critical. This requires detailed analysis of all the stages of riser operation.

There is a requirement for more refined methods and finite elements models to verify the operability of drilling riser systems in extreme conditions. Ultra deepwater and a harsh environment place higher demands on both the vessel and the drilling equipment. These higher demands results in the calculation of reduced operability envelopes for the various operations such as running, hang-off, drilling, connected non- drilling, etc.

Drilling riser system development through riser analysis is relatively common in the developed countries and many studies have been conducted previously [26], but it is still a new field in Korea and this is the significance of this study.

In this study, drilling riser system analysis is carried out as a process of drilling riser system development especially, focused on the drilling riser joint.

\section{Design consideration}

The design and optimization of a drilling riser system for harsh environments involves the assessment of a number of riser conditions and operations scenarios with variable design drivers on the riser stack-up. As a result, an iterative process is required between all stages of drilling riser system analysis.

For deepwater harsh environment drilling operation, vessel options include anchored or dynamically positioned semisubmersibles, or dynamically positioned drill ships.

The riser system has to be designed according to the international codes such as API RP 16Q [7]. Its requirement in particular is the maximum von Mises stress must be limited to less than $67 \%$ of the yield stress.

For the data of vessel and weather, a statistical assessment can produce the most probable maximum vessel heave, pitch, and roll response for all combinations of $\mathrm{H}_{\mathrm{s}}$ and $\mathrm{T}_{\mathrm{p}}$.

Especially, wave and Vortex induced vibration(VIV) fatigue analyses can optimize a little more the riser system stack-up. Wave fatigue analysis identifies the fatigue critical regions of the string.

The string then can be optimized to reduce the overall damage at this location and to smooth peaks. VIV induced fatigue damage can be reduced through VIV suppression devices such as fairings or strakes.

However, VIV suppression devices can increase drag loading. In high current environments this leads to larger riser deflections and reduced operability.

Optimum arrangement of the buoyant and riser joints within the string can reduce the effects of VIV. Placing riser joints at regular intervals between buoyant joints can disrupt current flow around the riser to help mitigate VIV. 


\section{Riser analysis}

A complete drilling riser analysis is a compilation of a number of analyses, which investigates the overall static and dynamic response of a drilling riser for various environmental loads, vessel loads and drilling loads.

Drilling riser systems are required to resist environmental loading whilst maintaining small flex joint angles for optimum utility. In shallow water, this may be achieved by the use of standard joints without using buoyancy and a low top tension. In deepwater however, increased riser tension and specific stack-up configurations are required for productive operation.

In the riser system analysis, the riser system is modeled as a tensioned bema subjected to loads throughout its length, and with boundary conditions at each end. The tensioned beam element descriptions include riser geometry, riser mass, and riser material properties. Loading on the riser includes internal and external pressures as well as environmental loads caused by waves and currents.

Top boundary conditions generally include top tension, vessel offsets and motions as well as a description of the rotational stiffness of the upper flex/ball joint. Typically, required top tension depends on the drilling fluid density. The bottom boundary condition may result from either a connected or disconnected riser. The boundary condition of a disconnected riser should include the mass of either the BOP stack or only the LMRP depending on the situation.

Drilling riser analysis has been performed by the commercial code, DeepRiser. The DeepRiser is an integrated engineering application used across the drilling industry and has been developed specially to optimize and streamline the design and analysis of drilling riser system.

Environmental parameters for riser analysis are as follows. The design water depth is plainly one of the major starting points for the riser design. It should be noted that the number of bare joints as well as the blow out preventer (BOP) and lower marine riser package (LMRP) weights have to be checked versus the hook load capacity during the deployment phases.

Deepwater drilling operations are sensitive to ocean currents due to the length of the riser and the large top tensions required to support the riser string. The current profiles and intensity determine the riser top and bottom end angles. According to API RP 16Q, in the drilling connected mode these angles have to be less of $2^{\circ}$ in static conditions and $4^{\circ}$ in dynamic conditions.

Wave action influences the riser system design in two ways. It contributes to the hydrodynamics loads acting on the riser. And it affects the riser top end motions through the rig RAOs (Response Amplitude Operators).

Deepwater drilling riser analysis provides a means for identifying the critical stages of the drilling program and enables strategies to be developed to combat loss of riser operability.

By the static analysis of drilling riser system, stack-up configuration of the system and the designed thickness of riser pipe were evaluated. Static analysis is not affected by the wave and the basic specifications of the system are evaluated through the calculation of loads and stress on the riser system. 
Table 1 shows the operating conditions such as wave, current, and winds in the drilling condition. Table 2 shows the operating condition in the hurricane return period. Generally, hurricane return period of 20 years is sufficient in the drilling riser analysis.

The problem of dynamic behavior of drilling riser, formulated by equations of motion, may be solved by the finite element method. Dynamic analysis includes the load exerted by the time varying wave force and the platform surge motion.

Table 1: Drilling condition.

\begin{tabular}{|c|l|l|}
\hline \multicolumn{2}{|c|}{ Drilling conditions } \\
\hline \multirow{2}{*}{ Wave } & Hs (m) & 3 \\
\cline { 2 - 3 } & T p (s) & 9 \\
\hline \multirow{2}{*}{ Current } & Surface $(\mathrm{m} / \mathrm{s})$ & 0.5 \\
\cline { 2 - 3 } & Mid (m/s) & 0.3 \\
\hline \multirow{2}{*}{ Wind } & 1 hour $(\mathrm{m} / \mathrm{s})$ & 20 \\
\hline
\end{tabular}

Table 2: Hurricane return period in Gulf of Mexico(GoM).

\begin{tabular}{|c|c|c|c|}
\hline \multicolumn{2}{|c|}{ Hurricane Return Period (Y) } & 10 & 20 \\
\hline \multirow{2}{*}{ Wave } & Hs (m) & 10 & 13.3 \\
\cline { 2 - 4 } & $\mathrm{T} \mathrm{p} \mathrm{(s)}$ & 13 & 14.4 \\
\hline \multirow{2}{*}{ Current } & Surface (m/s) & 1.65 & 2 \\
\cline { 2 - 4 } & Mid (m/s) & 1.24 & 1.5 \\
\hline Wind & 1 hour (m/s) & 33 & 40.1 \\
\hline
\end{tabular}

\section{Results and discussion}

Drilling riser system stack-up for $10,000 \mathrm{ft}(3,000 \mathrm{~m})$ water depth is conducted with riser system's total wet weight of 800 ton. Tensioner system is used to apply vertical force to the top of the drilling riser to control its stresses and displacements. The system is normally located on the drilling vessel near the periphery of the drill floor. The drilling riser system is deployed from a drillship equipped with six direct-acting riser tensioner systems as shown in Table 3. 
Table 3: Specifications of hydraulic tensioner.

\begin{tabular}{|c|c|}
\hline Number of lines & 6 \\
\hline Dynamic tension limit & 4,144 kips \\
\hline Tensioner efficiency & 0.95 \\
\hline
\end{tabular}

In order to verify the reliability of analytical results, calculation results are compared with the results of advanced research institution.

Figure 2(a) shows the static analysis results in extreme drilling conditions. Two results show a similar Von Mises stress values with the change of offset of drillship. Dynamic analysis results also show a similar trend for the UFJ angles in maximum drilling conditions as shown in Fig. 2(b).

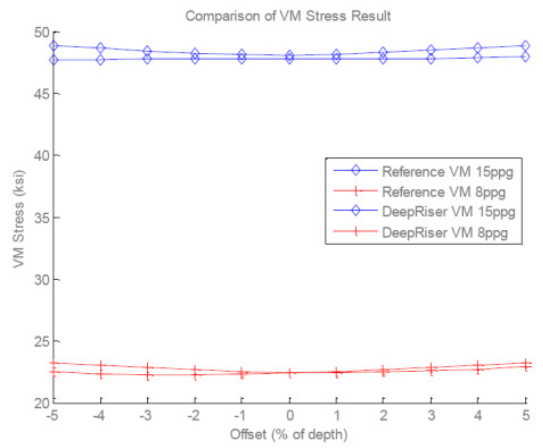

(a) Von Mises stress

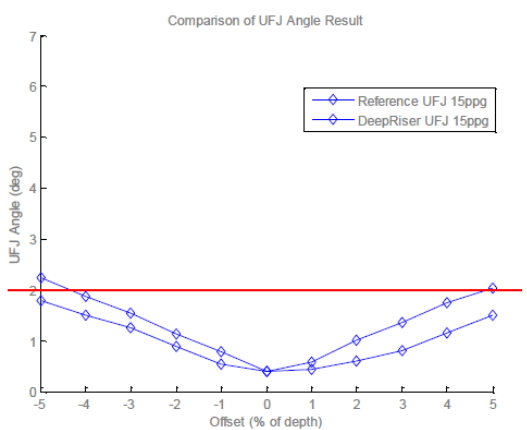

(b) UFJ angle limits

Figure 2: Comparison of calculated results.

In the case of drilling riser system's accidents, once the LMRP has disengaged from the BOP, the column of drilling mud is no longer supported by any system and starts to collapse. Mud will flow from the base of the LMRP until such time as the pressure of mud column reaches hydrostatic equilibrium with the pressure of surrounding seawater. The collapse pressure calculation is performed under this circumstance.

For the specifications of drilling riser joint such as O.D. of 21 inches, thickness of 0.875 inches, and material of API X-80 the inside depth of the riser joints which is emptied due to any accident is calculated as 4,468 ft as shown in Fig. 1.

At this time, the pressure of the outside seawater on the riser joint is $1,897 \mathrm{psi}$. This is lower than the collapse pressure presented from API 5C3 code is 3,283 psi. So the riser joint designed in this study is evaluates to be safe for the $10,000 \mathrm{ft}$ operating condition. 


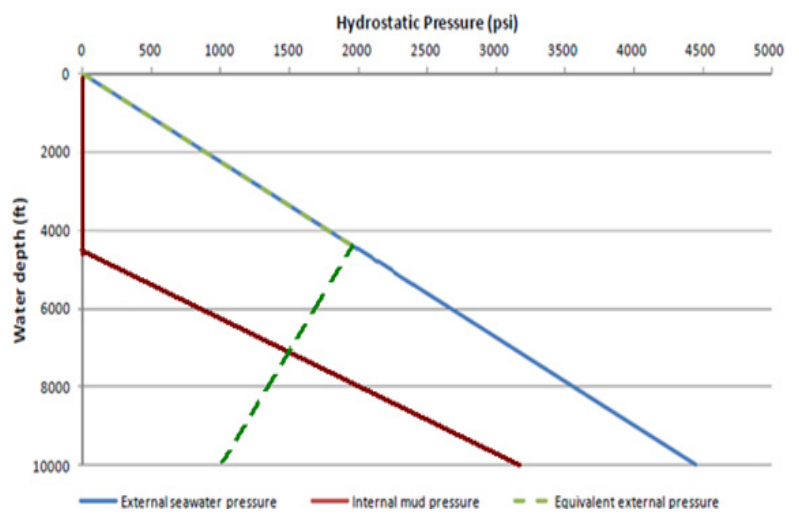

Figure 3: Collapse pressure calculation.

Von Mises stress is called as effective or equivalent stress, Von Mises stress is used in the Von Mises yield stress conditions.

In this study, for the safety condition of drilling riser system in the water depth of 10,000 ft, two type of drilling muds (8.56 ppg and $14 \mathrm{ppg}$ ) are used.

For the 14 ppg mud, the maximum Von Mises stress is calculated as $40.8 \mathrm{ksi}$. This is smaller than the allowable stress criteria ( $53.6 \mathrm{ksi}, 67 \%$ of yield stress) in the API RP 16Q. So in the Von Mises stress calculation, the riser joint is also evaluated to be safe for the $10,000 \mathrm{ft}$ operating conditions.

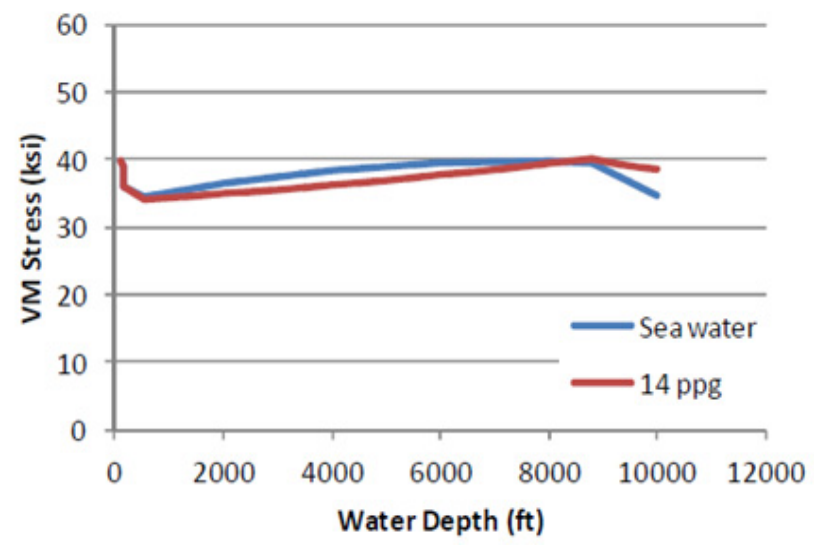

Figure 4: Von Mises stress of static analysis.

Look at the results of dynamic analysis, the effects of the thickness changes of the drilling riser joints are compared in the view of the maximum and minimum effective tensions, etc.

In this study, designed thickness of the riser joint is 0.875 inches. And $7 \%$ thin and thick target analyses for the designed thickness are conducted. 
As shown in Table 4, the effective tension has been very influential in changing with the stiffness of riser joints due to the changes of the pipe's thickness. But in all cases, Von Mises stress is within the permissible range and variation of the thickness don't change the angle of Flex Joint.

Table 4: $\quad$ Comparison with riser pipe depth change.

\begin{tabular}{|c|c|c|c|c|}
\hline \multicolumn{2}{|c|}{ Thickness (inch) } & 0.813 & 0.875 & 0.938 \\
\hline \multicolumn{2}{|c|}{$\begin{array}{l}\text { Max. Effective Tension } \\
\text { (kips) }\end{array}$} & 2,568 & 2,489 & 2,381 \\
\hline \multicolumn{2}{|c|}{$\begin{array}{l}\text { Min. Effective Tension } \\
\text { (kips) }\end{array}$} & 454.3 & 472.8 & 498.9 \\
\hline \multicolumn{2}{|c|}{ Max. Von Mises Stress (ksi) } & 49.6 & 45.0 & 40.6 \\
\hline \multirow{2}{*}{$\begin{array}{l}\text { Flex } \\
\text { Joint } \\
\text { Data }\end{array}$} & $\begin{array}{l}\text { Max. UBJ } \\
\text { Angle }\end{array}$ & 4.57 & 4.57 & 4.57 \\
\hline & Max. LBJ Angle & 0.039 & 0.039 & 0.039 \\
\hline
\end{tabular}

Next, the mud density dependences on the drilling riser analysis results are shown in Table 5. Two mud density values considered are $8.56 \mathrm{ppg}$ and $15 \mathrm{ppg}$.

In the case of $15 \mathrm{ppg}$ mud density, the total weight of the drilling riser system is largely increased. Therefore, the effective tension and Von Mises stress are also increased accordingly. That is, in the case of $15 \mathrm{ppg}$ mud density, the Von Mises stress exceeds the permitted range of $53.6 \mathrm{ksi}$ proposed from API RP 16Q.

Mud density of $8.56 \mathrm{ppg}$ is the scenario of the hang-off analysis. In this case, seawater is induced into the drilling riser system by any accident.

The change of mud density affects the change of Flex joint angle. However, in the case of 15 ppg mud density, it is favorable in the change of Flex joint angle.

Table 5: Comparison with mud density change.

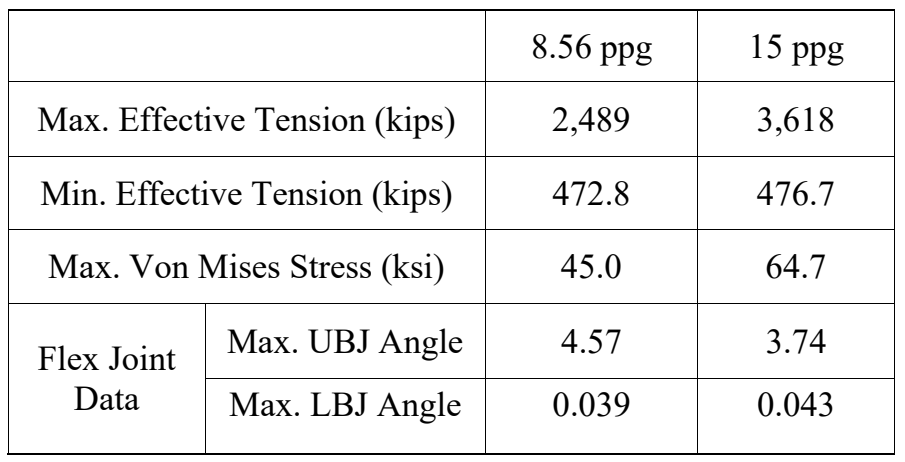


In the situation of disconnected hang off mode, the fluctuating axial tension should remain positive when the vessel heaves in order to avoid any slackening or dynamic buckling of the riser. Hurricane or in dangerous situations, any part of the drilling riser system are disconnected and the drilling unit turns back. That is, hang-off analyses are carried out.

In this case, there are two ways to turn back with the connection to the LMRP and BOP or only LMRP. In this study, the calculation is performed for both cases for the maximum drilling environmental conditions.

Looking at the results of the calculation in Fig. 5, 2,290 kips tension is acting in the case of BOP and LMRP hang-off (Fig. 5(a)). In the case of only LMRP hang-off (Fig. 5(b)), 1,900 kips tension is acted on the system. In both cases, the calculated tensions are smaller than those in drilling operations. So, the disconnected analysis shows the reliability of the drilling riser design.

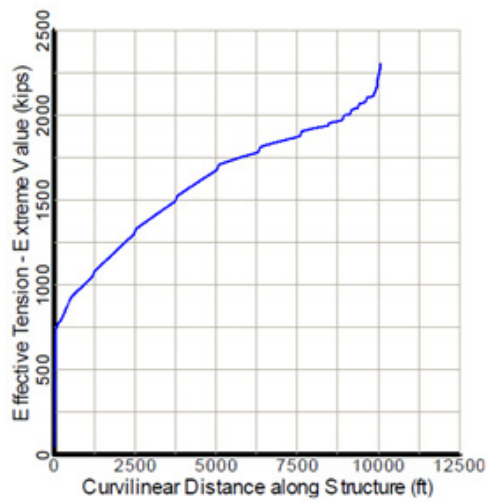

(a) BOP and LMRP hang-off

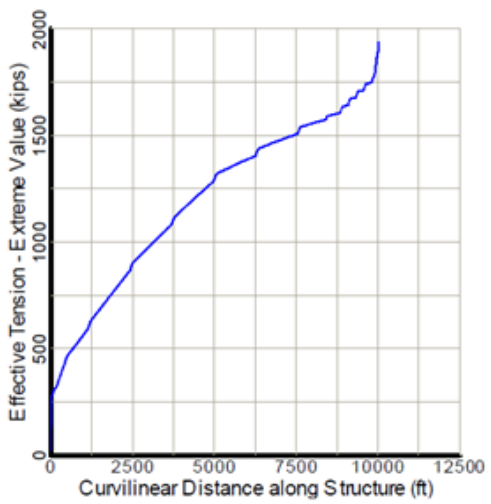

(b) LMRP hang-off

Figure 5: Comparison of hang-off analysis.

\section{Conclusions}

Deepwater drilling riser system analysis is quite complex and is required to define operational limits and top tension requirements under in-service loadings.

In this study, drilling riser system analysis is carried out as a process of drilling riser sys development especially focused on the drilling riser joint. In the drilling riser system analysis, collapse pressure and allowable stress calculations are performed for the $10,000 \mathrm{ft}$ water depth.

In the collapse pressure calculation, the outside seawater pressure on the riser joint is 1,897 psi. This is lower than the collapse pressure of 3,283 psi proposed from API 5C3 code. For the 14 ppg mud density, the maximum Von Mises stress is calculated as $40.8 \mathrm{ksi}$. This is smaller than the allowable stress criteria (53.6 ksi, $67 \%$ of yield stress) proposed from the API RP 16Q. 


\section{Acknowledgement}

This research was supported by the Development of 500Mpa URF \& SIL 3 Manifold and Subsea System Engineering for Deepsea Field Project (15-9806) of the KIGAM funded by the Ministry of Trade, Industry and Energy of Korea.

\section{References}

[1] Lang, D., Williams, D., Calculation of minimum top tension requirements for emergency disconnect of deepwater drilling risers, Deep offshore technology international, pp. 1-20, 2010.

[2] Guesnon, J., Gaillard, C., and Richard, F., Ultra deep water drilling riser design and relative technology, Oil \& Gas Science and Technology, Vol. 57, No. 1 pp. 39-57, 2002.

[3] Williams, D., Analysis of drilling risers in harsh and deepwater environments, Offshore magazine, 2009.

[4] Cao J., Design of deepwater tower riser for west of Africa application, Offshore Technology Conference 21551, 2011.

[5] Walters, D., Thomas, d., and Hatton, S., Design and optimization of top tension risers for ultra deep water, Floating Production Systems 2004 Conference, pp. 1-19, 2004.

[6] Hariharan, M., Thethi, R., Drilling riser management in deepwater environments, 2 H Offshore Inc., 2009.

[7] Recommended Practice for Design, Selection, Operation and Maintenance of Marine Drilling Riser System, API. 